NASA/TM-2012-217727

\title{
Advanced Stirling Convertor Durability Testing: Plans and Interim Results
}

David W. Meer

Sest, Inc., Middleburg Heights, Ohio

Salvatore M. Oriti

Glenn Research Center, Cleveland, Ohio 


\section{NASA STI Program . . . in Profile}

Since its founding, NASA has been dedicated to the advancement of aeronautics and space science. The NASA Scientific and Technical Information (STI) program plays a key part in helping NASA maintain this important role.

The NASA STI Program operates under the auspices of the Agency Chief Information Officer. It collects, organizes, provides for archiving, and disseminates NASA's STI. The NASA STI program provides access to the NASA Aeronautics and Space Database and its public interface, the NASA Technical Reports Server, thus providing one of the largest collections of aeronautical and space science STI in the world. Results are published in both non-NASA channels and by NASA in the NASA STI Report Series, which includes the following report types:

- TECHNICAL PUBLICATION. Reports of completed research or a major significant phase of research that present the results of NASA programs and include extensive data or theoretical analysis. Includes compilations of significant scientific and technical data and information deemed to be of continuing reference value. NASA counterpart of peer-reviewed formal professional papers but has less stringent limitations on manuscript length and extent of graphic presentations.

- TECHNICAL MEMORANDUM. Scientific and technical findings that are preliminary or of specialized interest, e.g., quick release reports, working papers, and bibliographies that contain minimal annotation. Does not contain extensive analysis.

- CONTRACTOR REPORT. Scientific and technical findings by NASA-sponsored contractors and grantees.
- CONFERENCE PUBLICATION. Collected papers from scientific and technical conferences, symposia, seminars, or other meetings sponsored or cosponsored by NASA.

- SPECIAL PUBLICATION. Scientific, technical, or historical information from NASA programs, projects, and missions, often concerned with subjects having substantial public interest.

- TECHNICAL TRANSLATION. Englishlanguage translations of foreign scientific and technical material pertinent to NASA's mission.

Specialized services also include creating custom thesauri, building customized databases, organizing and publishing research results.

For more information about the NASA STI program, see the following:

- Access the NASA STI program home page at http://www.sti.nasa.gov

- E-mail your question to help@sti.nasa.gov

- Fax your question to the NASA STI Information Desk at 443-757-5803

- Phone the NASA STI Information Desk at 443-757-5802

- Write to: STI Information Desk NASA Center for AeroSpace Information 7115 Standard Drive Hanover, MD 21076-1320 
NASA/TM-2012-217727

AIAA-2012-4249

\section{Advanced Stirling Convertor Durability Testing: Plans and Interim Results}

David W. Meer

Sest, Inc., Middleburg Heights, Ohio

Salvatore M. Oriti

Glenn Research Center, Cleveland, Ohio

Prepared for the

10th International Energy Conversion Engineering Conference (IECEC)

sponsored by the American Institute of Aeronautics and Astronautics

Atlanta, Georgia, July 30-August 1, 2012

National Aeronautics and

Space Administration

Glenn Research Center

Cleveland, Ohio 44135 


\section{Acknowledgments}

This work is funded through the NASA Science Mission Directorate.

Trade names and trademarks are used in this report for identification only. Their usage does not constitute an official endorsement, either expressed or implied, by the National Aeronautics and Space Administration.

Level of Review: This material has been technically reviewed by technical management.

Available from

NASA Center for Aerospace Information 7115 Standard Drive

Hanover, MD 21076-1320
National Technical Information Service 5301 Shawnee Road Alexandria, VA 22312

Available electronically at http://www.sti.nasa.gov 


\title{
Advanced Stirling Convertor Durability Testing: Plans and Interim Results
}

\author{
David W. Meer \\ Sest, Inc. \\ Middleburg Heights, Ohio 44130 \\ Salvatore M. Oriti \\ National Aeronautics and Space Administration \\ Glenn Research Center \\ Cleveland, Ohio 44135
}

\begin{abstract}
The U.S. Department of Energy (DOE), Lockheed Martin Corporation (LM), and NASA Glenn Research Center (GRC) have been developing the Advanced Stirling Radioisotope Generator (ASRG) for use as a power system for space science missions. In support of this program, GRC has been involved in testing Stirling convertors, including the Advanced Stirling Convertor (ASC), for use in the ASRG. This testing includes electromagnetic interference/compatibility (EMI/EMC), structural dynamics, advanced materials, organics, and unattended extended operation. The purpose of the durability tests is to experimentally demonstrate the margins in the ASC design. Due to the high value of the hardware, previous ASC tests focused on establishing baseline performance of the convertors within the nominal operating conditions. The durability tests present the first planned extension of the operating conditions into regions beyond those intended to meet the product spec, where the possibility exists of lateral contact, overstroke, or over-temperature events. These tests are not intended to cause damage that would shorten the life of the convertors, so they can transition into extended operation at the conclusion of the tests. This paper describes the four tests included in the durability test sequence: 1) start/stop cycling, 2) exposure to constant acceleration in the lateral and axial directions, 3) random vibration at increased piston amplitude to induce contact events, and 4) overstroke testing to simulate potential failures during processing or during the mission life where contact events could occur. The paper also summarizes the analysis and simulation used to predict the results of each of these tests.
\end{abstract}

\section{Nomenclature}

$\begin{array}{ll}\text { AC } & \text { alternating current } \\ \text { ACU } & \text { ASC Control Unit } \\ \text { ASC } & \text { Advanced Stirling Convertor } \\ \text { ASRG } & \text { Advanced Stirling Radioisotope Generator } \\ \text { CSAF } & \text { Cold Side Adapter Flange } \\ \text { CWRU } & \text { Case Western Reserve University } \\ \text { DOE } & \text { Department of Energy } \\ \text { EDU } & \text { Engineering Development Unit } \\ \text { EU } & \text { Engineering Unit } \\ \text { GPHS } & \text { General Purpose Heat Source } \\ \text { GRC } & \text { NASA Glenn Research Center } \\ \text { ILS } & \text { Internal Limit Sensor } \\ \text { LMSSC } & \text { Lockheed Martin Space Systems Corp. } \\ \text { rms } & \text { root mean square } \\ \text { RWG } & \text { Reliability Working Group } \\ \text { SDL } & \text { Structural Dynamics Laboratory } \\ \text { SDM } & \text { System Dynamic Model }\end{array}$


SRG110 110 W Stirling Radioisotope Generator

TDC Technology Demonstration Convertor

\section{Introduction}

The Thermal Energy Conversion Branch at NASA Glenn Research Center (GRC) has been supporting the development of the Advanced Stirling Radioisotope Generator (ASRG). The ASRG has been identified for potential use on two of the three candidate Discovery 12 missions (Ref. 1). A key element of the ASRG project is providing life, reliability, and performance data for the Advanced Stirling Convertor (ASC). For this purpose, GRC has established a laboratory that is conducting extended operation of several ASCs (Ref. 2). The goal of this effort is to generate performance data over a sufficiently long period of time (tens of thousands of hours) to support probabilistic reliability analyses.

Due to the high value of the hardware, ongoing activity at GRC focuses on operation of hermeticallysealed ASCs at nominal operating conditions. The hermetic nature of those convertors makes inspection difficult. The convertors for the durability test feature a removable pressure vessel to allow for partial disassembly of the convertors and inspection of internal components. The purpose of the durability tests is to experimentally demonstrate the margins in the ASC design. The durability tests present the first planned extension of the operating conditions into regions beyond those intended to meet the ASC product specification, where the possibility exists of lateral contact, overstroke, or over-temperature events. These tests may operate the convertors in areas of negative margins at a reduced factor of safety, yet these tests are not intended to result in damage that could shorten the life of the convertors. The intent is that the convertors can transition into extended operation at the conclusion of the durability tests described in this document. ASC-E2 nos. 2 and 8 are the test articles for the durability testing.

\section{Background}

There were initially six types of tests considered that could subject the convertors to over-stressed conditions: static acceleration, random vibration, overstroke, shock, temperature, and radiation exposure. Several discussions were held with the ASRG Reliability Working Group (RWG), led by Lockheed Martin Space Systems Corp. (LMSSC), to review each test in terms of risk and benefit. The discussion considered if the parameter being proposed in the test was or could be covered adequately in a component-level test. The desire was for the durability tests to address aspects that are best served by convertor-level tests.

In some cases, the tests gained a slightly different purpose than was envisioned before the discussion. A steady- state acceleration test was considered valuable, but was contingent on finding a facility that could fit the project requirements in terms of cost, schedule, and technical capability. The random vibration test was initially intended to expose a convertor to levels exceeding qualification, but following the discussions it was decided that the vibration test should be used to simulate overstrokes during launch. No contacts are anticipated during launch, but the possibility was considered for the case of an uncharacteristically-rough launch environment. The overstroke test was initially intended to investigate damage to the convertor in the event of an unexpected loss of control. The controller has $\mathrm{N}+1$ redundancy, so overstroke due to a controller fault would only occur after multiple failures. This could also occur if controller card switch over did not happen as quickly as designed, or if a connection error were made during processing on the ground. The use of a solid-state switch makes a contact due to switch over unlikely. Also, a safe mate procedure exists to minimize the possibility of a connection error during ground processing. Thus, contact due to loss of control is not expected at any point during a mission, but is considered for these tests as such an event would be outside the nominal operating conditions. A shock test was considered, but this would be better tested at the generator level, and no facilities were identified that could exceed the shock levels already tested at LMSSC. Tests at temperatures outside of the ASC-E2 product spec might be undertaken on subsequent pairs of E2s as a part of extended operation and were discounted. Options for radiation tests were discounted due to existing data on radiation tolerance of materials and other ongoing tests. After the draft of the initial durability test plan, a test was added to investigate repeated starting and stopping of the convertors. 
With this, the list was reduced to four tests:

1. Exposing the convertor to multiple start and stop cycles to evaluate potential Xylan (Whitford Corporation) wear from motion before gas bearings are fully charged.

2. Exposing the convertor to a static g load to simulate reentry and landing on a planetary surface or a boost thruster during a mission. This test would investigate the response of the convertor moving components, as well as the possibility of Xylan wear when the static acceleration is applied in the lateral direction.

3. Exposing a convertor to random vibration with above-nominal piston amplitude to create a number of controlled contact events. This test would also serve to evaluate potential Xylan wear during the random vibration exposures.

4. Simulating a controller switchover error or connection error that would temporarily disable control and allow a limited number of contact events.

The idea was adopted to incorporate a bolt-on pressure vessel into the convertors for durability testing to allow inspection of internal components between the different tests. Inspection was chosen in favor of a period of extended operation to ascertain convertor health, as this reduced the required time between tests. Because of hardware availability, ASC-E2s nos. 2 and 8 were chosen as the test articles for these durability tests.

\section{Implementation}

The durability test plan is currently ongoing, with the first two of the four tests completed. ASC-E2 no. 8 was used for the start/stop durability test, while ASC-E2 no. 2 was used for the static g load test. Previous testing of ASC-E2s nos. 2 and 8 at GRC established baseline performance. ASC-E2 no. 2 was operated for $2,700 \mathrm{hr}$ at nominal conditions and then being returned to Sunpower. At this time it was outfitted with the removable pressure vessel. ASC-E2 no. 8 was not hermetically sealed prior to delivery, and all its operation thus far has been with the removable pressure vessel. Both convertors underwent an initial inspection before any durability test to define initial conditions of the convertor internal components for comparison later. This procedure consisted of removing the pressure vessel and partially disassembling the internal components to allow inspection of any surface markings and internal cleanliness. The GRC Stirling Research Laboratory (SRL) procedure, "Durability Test Convertor Inspection Procedure," fully describes the inspection process. Following each test, the convertor underwent a partial disassembly and inspection procedure to determine if any wear or damage had occurred. At the completion of the durability tests, the convertors will return to Sunpower for installation of the production pressure vessels and completion of the normal processing sequence before entering into the extended operation at GRC.

\section{Start/Stop Test}

Table I summarizes the various operating conditions for the start/stop test. These conditions represent what a flight convertor will experience during processing at Sunpower and Lockheed Martin Space Systems Corp. (LMSSC). The cold-end and pressure vessel temperatures represent those when the convertor is tested at low- and high-rejection temperature conditions. The number of cycles was chosen based on the number of tests planned for the flight convertors, which has been estimated to be up to 150 . Historical processing experiences of the ASRG-EU at LMSSC and the ASC-E2s at Sunpower were also considered. During processing of the ASRG-EU, the convertors underwent 44 start/stop cycles. During processing of ASC-E2s nos. 3 and 4 at Sunpower, for example, the convertors underwent 22 start/stop cycles. The number of cycles for the durability start/stop test was chosen to double the amount expected for a flight unit, hence the test plan consisted of 301 cycles. A flight convertor will undergo start/stop cycles in both the vertical and horizontal orientation, thus both arrangements were tested. Since the hotend temperature plays a negligible role in the operation of the gas bearings, all start/stop cycle testing was performed at a hot-end temperature of $23{ }^{\circ} \mathrm{C}$. An inspection was performed following the three vertical orientation tests and also following the horizontal orientation test. 
TABLE I.-OPERATING CONDITIONS FOR START/STOP TEST

\begin{tabular}{|c|c|c|c|c|}
\hline $\begin{array}{c}\text { Number of } \\
\text { cycles }\end{array}$ & $\begin{array}{c}\text { Hot-end } \\
\text { temperature, } \\
{ }^{\circ} \mathrm{C}\end{array}$ & $\begin{array}{c}\text { Cold-end } \\
\text { temperature, } \\
{ }^{\circ} \mathrm{C}\end{array}$ & $\begin{array}{c}\text { Pressure vessel } \\
\text { temperature, } \\
{ }^{\circ} \mathrm{C}\end{array}$ & Orientation \\
\hline 67 & 23 & 23 & 23 & Vertical \\
\hline 67 & 23 & 38 & 46 & Vertical \\
\hline 67 & 23 & 52 & 61 & Vertical \\
\hline \multicolumn{7}{|c|}{ Inspection } \\
\hline 100 & 23 & 23 & 23 & \\
\hline
\end{tabular}

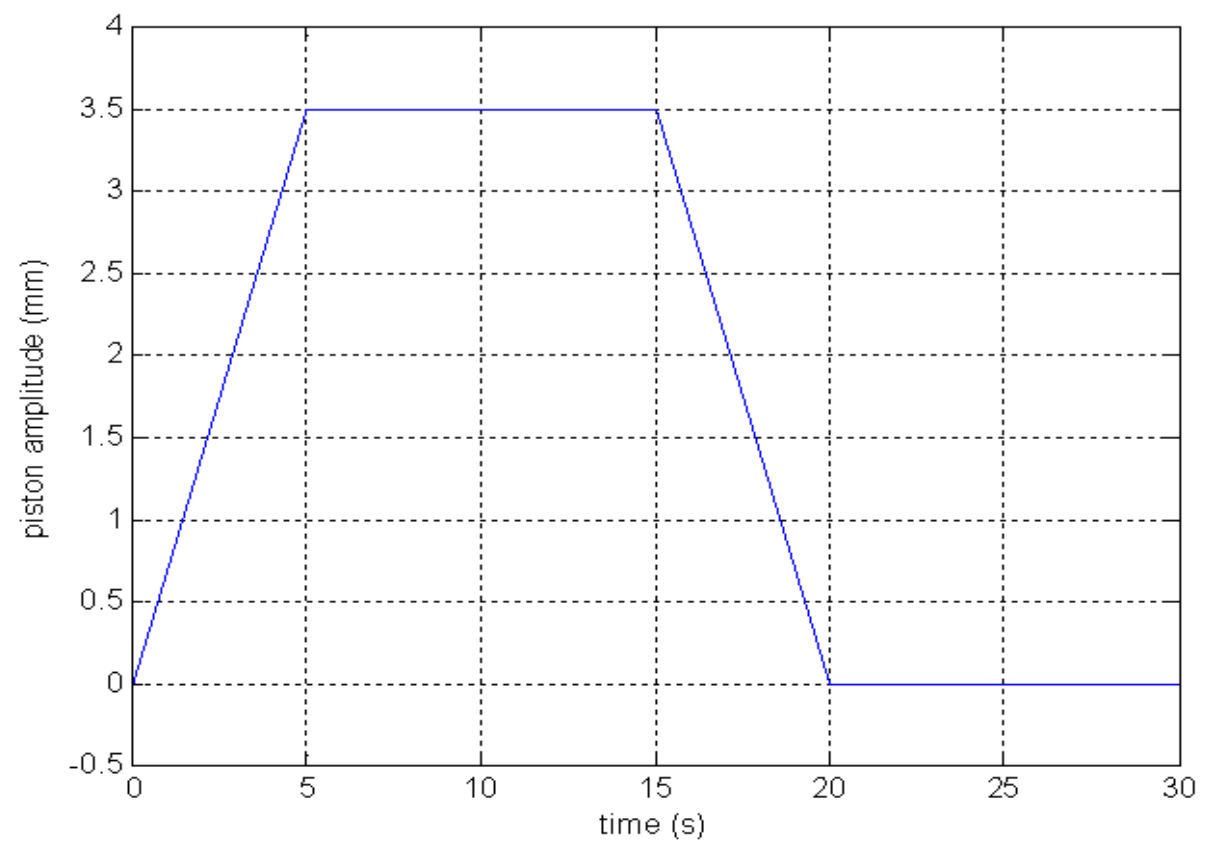

Figure 1.-Amplitude profile for start /stop test.

All of these cycles were performed using the piston amplitude profile shown in Figure 1. The ramp rate was designed to reach the maximum setpoint in $5 \mathrm{~s}$. The piston amplitude was held at $3.5 \mathrm{~mm}$ for $10 \mathrm{~s}$ and then ramped down to zero in $5 \mathrm{~s}$. The rest time between cycles was $10 \mathrm{~s}$ for vertical operation to prevent the piston from drifting and one minute for horizontal operation. The AC bus voltage required to operate at $3.5 \mathrm{~mm}$ at each operating condition varied and was determined at the beginning of each step of the testing.

\section{Static g Load (Centrifugal Acceleration Test)}

The second test in the durability test sequence utilized a centrifuge to expose the convertors to a constant acceleration load for a specified period of time. The ASRG product specification requires operation while exposed $18 \mathrm{~g}$ of acceleration. This acceleration could be transferred to the convertor in either the axial or lateral direction. The axial condition could occur if the ASRG were on a craft launched by a spinstabilized booster, such as the STAR48. In this case, if the ASRG were attached so that the axis of the convertors was in the radial direction of the spin, the convertors would experience static centrifugal acceleration along their piston motion axes. During a planetary decent, the convertors would experience a static $g$ load in the lateral direction.

During the planning stage of this test, the anticipated static g load requirement for an ASRG flight was estimated at $30 \mathrm{~g}$. Simulations were performed to evaluate the effect of $30 \mathrm{~g}$ on the convertor 
operation. The results showed that both the piston and the displacer motions shift in the direction of the acceleration, but still have sufficient margin in the "out" direction. The results showed that there could be displacer contact with the heater head dome when the acceleration is applied towards the heater head, or the inwards direction. Note that while a static analysis would determine the steady-state shift inward or outward of the piston and displacer motion, the model also takes into account the transient response of the system to determine if a potential problem could occur in that phase of the test.

The specification was later altered to require only up to $18 \mathrm{~g}$. The requirement also consists of a profile of the static acceleration as a function of time. The landing profile consists of a dwell at the peak of $18 \mathrm{~g}$ acceleration for $10 \mathrm{~s}$. A facility at Case Western Reserve University (CWRU) was identified for this test that could achieve the desired static acceleration. Figure 2 illustrates the $18 \mathrm{~g}$ requirement profiles, as well as the profile attainable by the CWRU centrifuge facility. As can be seen, the centrifuge is not capable of ramping quickly enough to match the ramp of the landing profile nor the ramp of the STAR48 profile. This means the convertor will be over exposed, which is the intent of the durability tests.

A mounting fixture was designed to interface the convertor with the CWRU centrifuge and permit multiple orientations of the convertor (Figure 3). The centrifuge testing consisted of these steps:

- $18 \mathrm{~g}$ axial, heater head inwards

- $18 \mathrm{~g}$ axial, heater head outwards

- 8 g lateral, heater head down

- Inspection

- $12 \mathrm{~g}$ lateral, heater head down

- Inspection

- $18 \mathrm{~g}$ lateral, heater head down, rotated $90^{\circ}$ in fixture, stalled convertor after $10 \mathrm{~s}$ of $18 \mathrm{~g}$

- Inspection

Since the spin-up portion of the test was so much slower than the required profile, the decision was made to stall the convertor after the $10 \mathrm{~s}$ at $18 \mathrm{~g}$ was completed. Operating during the latter half, when the centrifuge is slowing down, would double the static acceleration exposure for this stage. The spin-up portion plus the $10 \mathrm{~s}$ of $18 \mathrm{~g}$ still exceed the area under the landing profile sufficiently to serve the purpose of this durability test.

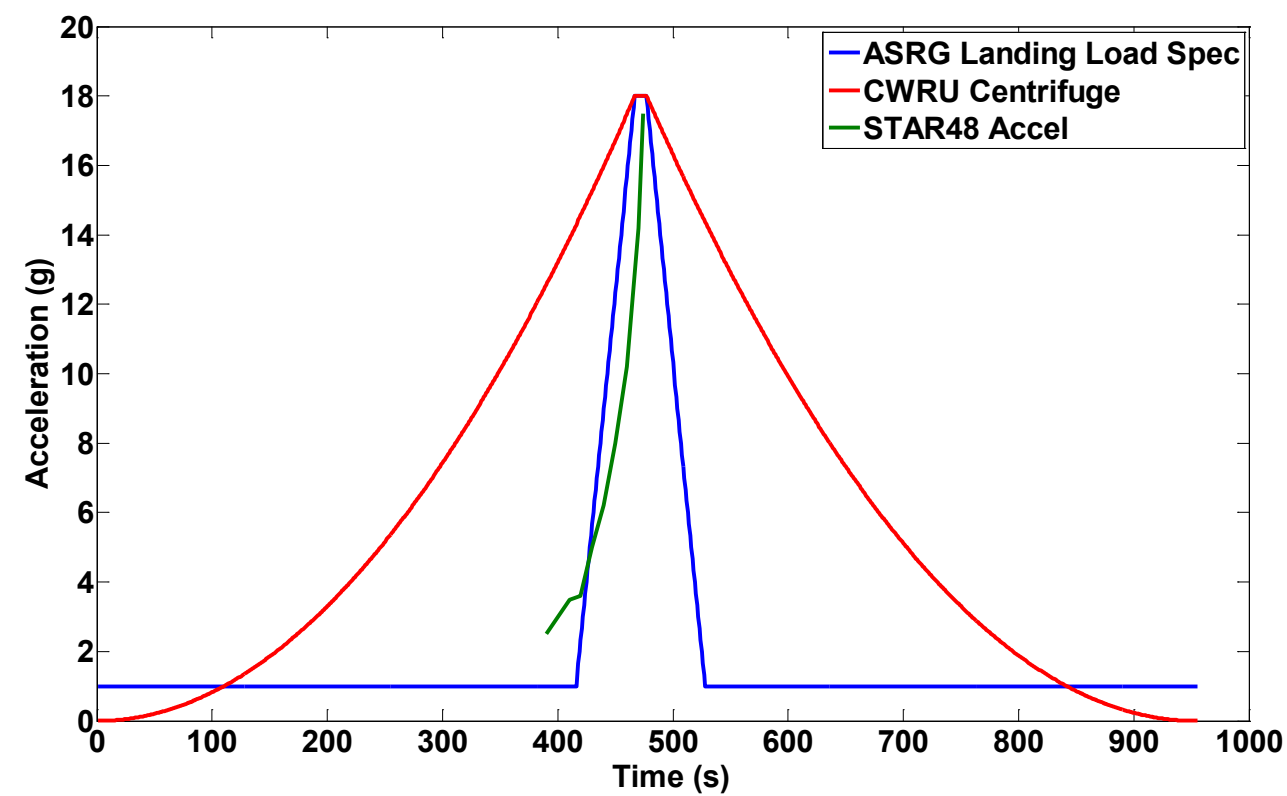

Figure 2.-Graph of static acceleration profiles for the flight requirement the profile attainable by the CWRU facility. 

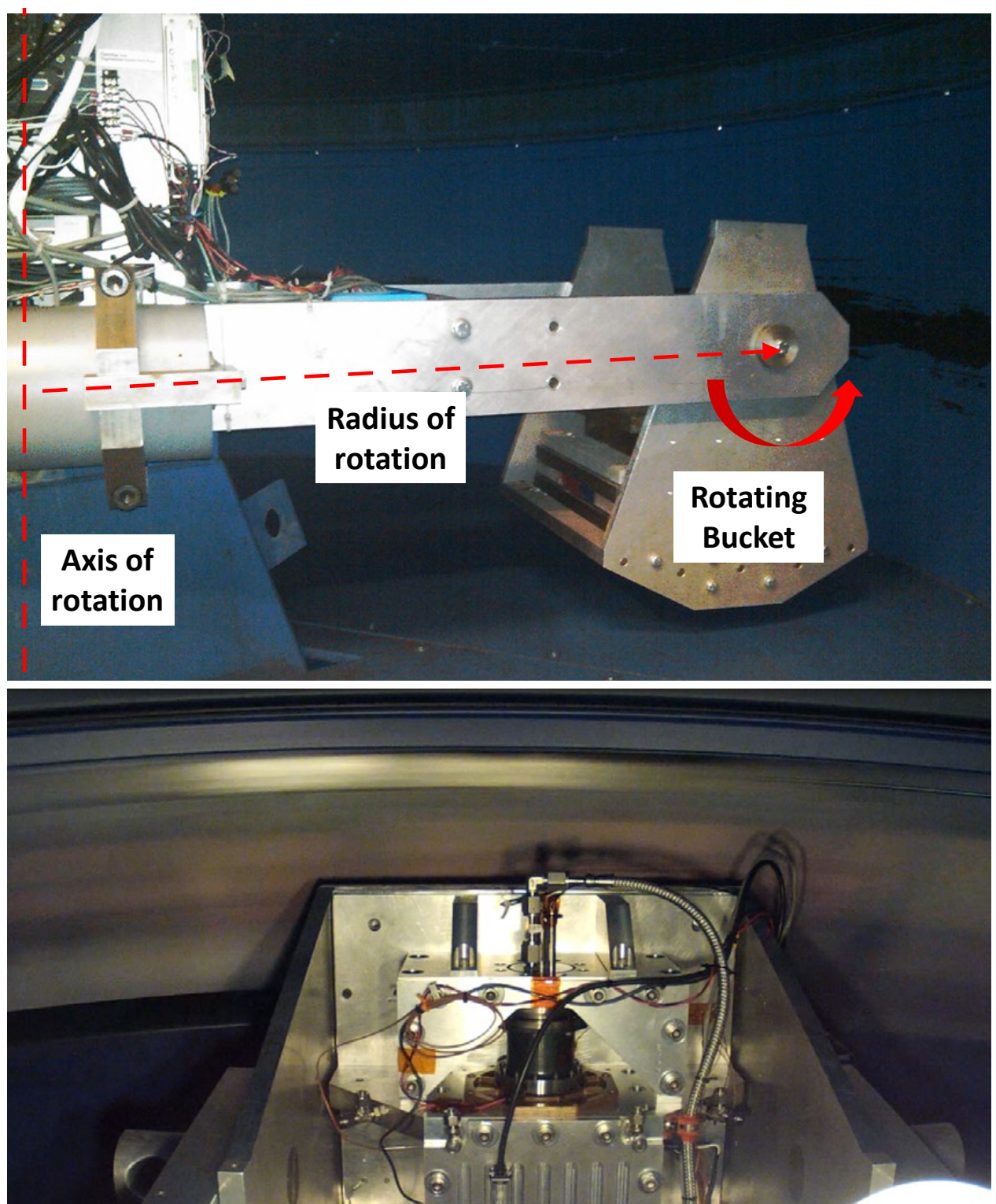

Figure 3.-Centrifugal acceleration test: photo of rotating arm/bucket (upper) and video frame from $18 \mathrm{~g}$ lateral test with heater head down (lower).

\section{Contact During Launch Test}

Figure 4 presents results from earlier vibration testing to qualification levels using ASC-E no.1 under control of the LMSSC engineering development unit (EDU) 1 ASC control unit (ACU). This test was conducted in March 2009. The figure shows the maximum piston position excursions as a function of vibration level in $\mathrm{g}_{\mathrm{rms}}$. In this case, the convertor was operated at a nominal piston amplitude of $4.25 \mathrm{~mm}$ with a hot-end temperature of $650{ }^{\circ} \mathrm{C}$ and a cold-end temperature of $50{ }^{\circ} \mathrm{C}$. During this test, both the in (toward the heater head) and out (away from the heater head) safety limits were set $0.5 \mathrm{~mm}$ away from the hard stops. As the plot shows, the safety limit was exceeded once during testing at the qualification level. Note that the input spectra used during this test was shaped based on the results of the dynamic test to qualification level of the ASRG Engineering Unit (EU) conducted at LMSSC in the spring of 2008. For details of the overall vibration test approach for ASC units, see Reference 3. 

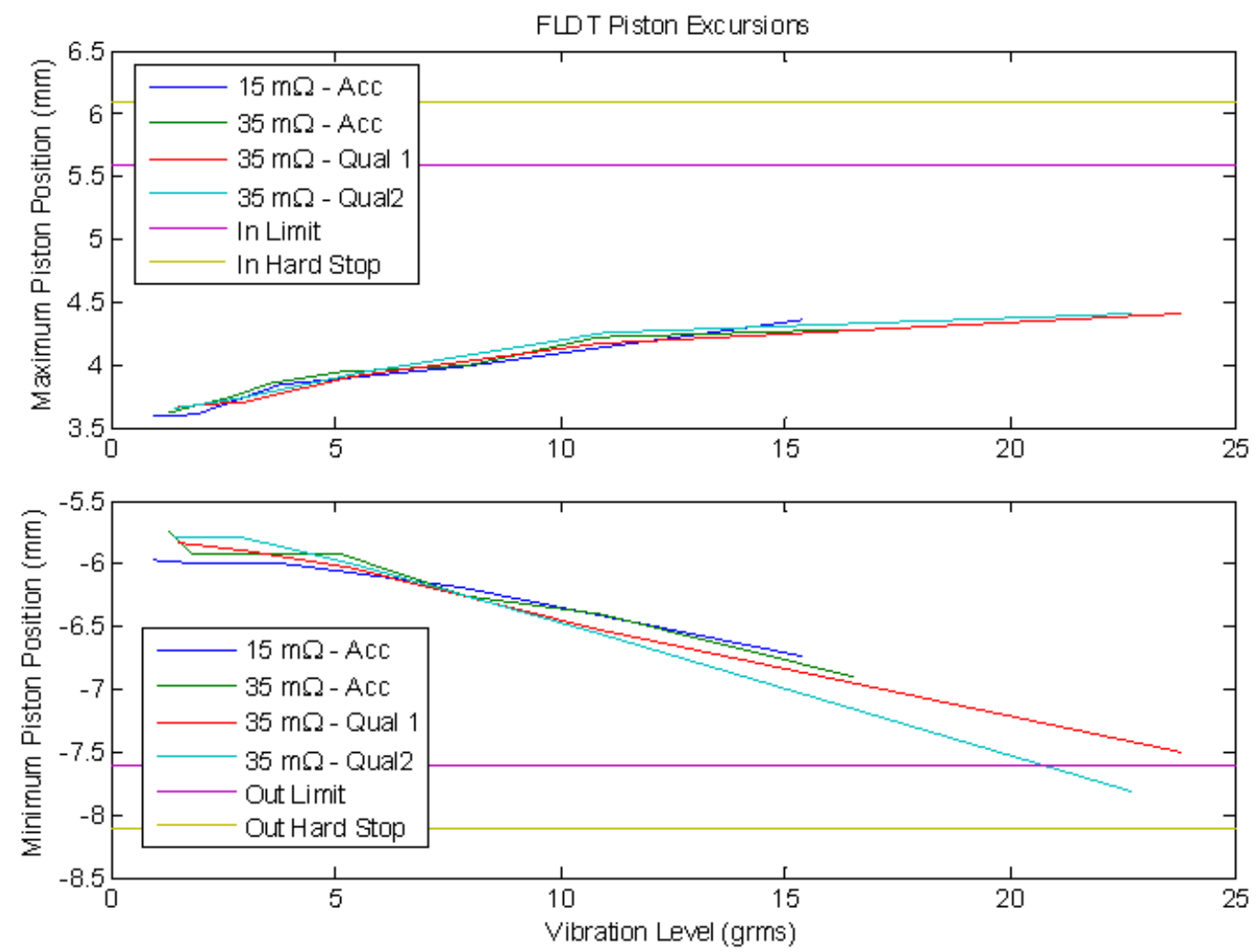

Figure 4.-Piston amplitude excursions as a function of vibration input level.

The first step in specifying details for this test utilized the GRC-developed system dynamic model (SDM) to predict vibration level or operational amplitude required to lead to contact events. Since qualification level vibration with the shaped input spectra already approaches the maximum capabilities of the shakers in the GRC's Structural Dynamics Laboratory (SDL), the most likely adjustment would involve an increase in piston amplitude during operation. Due to the random nature of the vibration testing, some adjustment during the test is likely.

Besides position sensors incorporated into the ASCs, several alternative methods for determining the actual number of contact events are under investigation, including acoustic sensors attached to the convertor, microphones located near the convertor, and additional high-frequency accelerometers. This test began in June 2012. The steps consist of the following:

- Vibration exposure at workmanship level in all three axes

- Inspection to evaluate workmanship vibe effect on Xylan surfaces

- Lateral vibration exposure at qualification level

- Inspection

- Axial vibration exposure at qualification level, with increased piston amplitude

- Inspection

The first stage, workmanship-level vibration, has been completed. The inspection for this stage is currently being completed. 


\section{Overstroke Test}

The goal of the fourth durability test is to simulate possible contact events during processing or during the mission life. An off-nominal switchover within the ACU from one control card to another could result in an overstroke. At the present time, the estimated switchover time due to relay closure is $1 \mathrm{~ms}$. Within this timespan, SDM simulations have shown the possibility of collisions, depending upon the point in the cycle at which the switchover is initiated. Analysis has been performed to determine the contact velocities at which permanent component deformation will occur. These will be used to develop the test plan, during which the piston amplitude will be increased until overstroking occurs. The goal is to prevent permanent deformation by staying below the calculated threshold velocities.

\section{Test Results}

\section{Start/Stop Test}

The convertor was disassembled, inspected, and evaluated following the vertical orientation tests, and also following the horizontal orientation tests. The primary purpose of the start/stop test was to characterize the anticipated wear on the Xylan surfaces of the convertor by doubling the number of start/stop cycles seen by a typical flight convertor. No noticeable wear resulted after either the vertical or horizontal tests. Based on the photographs and visual inspection by a Sunpower technician experienced in the assembly, disassembly, and production of ASCs, the Xylan surfaces did not exhibit any detectable change as a result of the start/stop cycles. Some light buffing was noted on the piston, on the side facing downward during the horizontal testing. In addition, the lint-free cloths used to wipe the piston and displacer as part of the disassembly process showed no signs of any Xylan or other foreign materials.

Table II summarizes the gas bearing flows measured at the 16 bearing pads on the piston at three points in time: before testing, after vertical testing, and after horizontal testing. The data demonstrate that the testing did not significantly change the gas bearing flow. Table III compares the breakaway torques measured during the disassemblies to the installation torque specification. The breakaway torque values do not correspond exactly to the installation torque value because the fasteners were installed without threadlocker. However, these torque data suggest the fasteners did not loosen due to the start/stop cycling. In conclusion, the anticipated start/stop cycling of a convertor during a flight life cycle will not adversely affect the Xylan-coated surfaces within the ASC.

TABLE II.-GAS BEARING FLOWS

\begin{tabular}{|c|c|c|c|}
\hline $\begin{array}{c}\text { Bearing } \\
\text { no. }\end{array}$ & $\begin{array}{c}\text { Pre-test, } \\
\%\end{array}$ & $\begin{array}{c}\text { Post-vertical, } \\
\%\end{array}$ & $\begin{array}{c}\text { Post-horizontal, } \\
\%\end{array}$ \\
\hline O.D. 1 & 7.5 & 7.5 & 7.5 \\
O.D. 2 & 10.5 & 10.0 & 10.5 \\
O.D. 3 & 11.5 & 11.0 & 11.5 \\
O.D. 4 & 9.0 & 9.0 & 9.5 \\
O.D. 5 & 3.5 & 3.5 & 3.5 \\
O.D. 6 & 3.5 & 3.5 & 3.5 \\
O.D. 7 & 5.0 & 5.0 & 5.5 \\
O.D. 8 & 5.0 & 5.5 & 5.5 \\
\hline I.D. 1 & 25.5 & 25.0 & 25.0 \\
I.D. 2 & 29.0 & 28.5 & 28.0 \\
I.D. 3 & 31.0 & 30.5 & 29.5 \\
I.D. 4 & 28.0 & 28.5 & 28.0 \\
I.D. 5 & 20.0 & 20.0 & 20.0 \\
I.D. 6 & 19.5 & 19.5 & 19.5 \\
I.D. 7 & 21.0 & 21.5 & 21.5 \\
I.D. 8 & 21.5 & 22.0 & 21.5 \\
\hline
\end{tabular}


TABLE III.-BREAKAWAY TORQUE

\begin{tabular}{|l|c|c|c|}
\hline \multicolumn{1}{|c|}{ Fastener } & $\begin{array}{c}\text { Post vertical, } \\
\text { lbf-in. }\end{array}$ & $\begin{array}{c}\text { Post horizontal, } \\
\text { lbf-in. }\end{array}$ & $\begin{array}{c}\text { Nominal install } \\
\text { specification, } \\
\text { lbf-in. }\end{array}$ \\
\hline Flex rod nut & -7.590 & -7.727 & 8.4 \\
\hline Spring fastener 1 & -5.496 & -5.502 & \\
Spring fastener 2 & -6.579 & -5.848 & 6.8 \\
Spring fastener 3 & -5.599 & -5.623 & \\
Spring fastener 4 & -6.289 & -5.439 & \\
\hline Magnet can fastener 1 & -4.675 & -4.980 & \\
Magnet can fastener 2 & -4.447 & -4.831 & \\
Magnet can fastener 3 & -4.859 & -5.150 & \\
Magnet can fastener 4 & -4.465 & -4.868 & \\
Magnet can fastener 5 & -4.534 & -5.003 & \\
Magnet can fastener 6 & -4.703 & -4.648 & \\
\hline
\end{tabular}

\section{Centrifugal Acceleration Test}

All segments of the centrifugal acceleration test were completed by May 7, 2012. During the first segment, $18 \mathrm{~g}$ in the axial direction with the heater head inwards, the convertor exhibited a temporary outward drift of the piston center of oscillation. The effect was large enough to approach the established safety limit, but did not exceed it. The convertor returned to normal operation once the centrifugal acceleration was removed. The convertor exhibited little response during the $18 \mathrm{~g}$ exposure in the axial direction with the heater head outwards. SDM simulations suggested the displacer would come close to the safety limit as it would be pushed towards the heater head, but this was not observed during the test. The convertor was then exposed to $8 \mathrm{~g}$ in the lateral direction. Analysis suggested the gas bearing ability would be overcome once the lateral acceleration exceeded $3 \mathrm{~g}$. Thus, rubbing would be expected during the lateral test, and it was observed. During this lateral exposure, the convertor power output was temporarily reduced by $18 \mathrm{~W}$. This was due to a temporary reduction in piston and displacer amplitude, which would be expected if the static acceleration were producing cylinder contact. The convertor performance returned to normal once the lateral acceleration was removed. Following the $8 \mathrm{~g}$ lateral test, the convertor was transported to Sunpower, disassembled, and inspected. No signs of Xylan surface wear nor debris generation were observed. There was some evidence of buffing on the displacer body in line with the static acceleration. The convertor was then operated while exposed to $12 \mathrm{~g}$ of lateral acceleration. The results were similar. A temporary reduction in power output and amplitude was observed. No change in the state of the displacer body surface was observed upon disassembly and inspection. No new evidence of wear was observed. The convertor was then operated with $18 \mathrm{~g}$ in the lateral direction. For this test the convertor was installed in the test fixture rotated $90^{\circ}$ relative to previous installations. Since the displacer body exhibited evidence of buffing, this decision was made so that the effect of the $18 \mathrm{~g}$ lateral acceleration could be isolated to a new area on the moving components. Also, the convertor was stalled following the $10 \mathrm{~s}$ plateau at $18 \mathrm{~g}$. The ramp up and $10 \mathrm{~s}$ plateau was deemed sufficient exposure for durability purposes. While exposed to $18 \mathrm{~g}$ lateral acceleration, the convertor power output was reduced from 55 to $24 \mathrm{~W}$, a reduction of approximately $30 \mathrm{~W}$. The convertor was then restarted after the centrifuge stopped spinning, at which time it returned to its nominal performance with a power output of $55 \mathrm{~W}$. The subsequent inspection showed a buffing mark on the displacer in the new area, but no debris was generated, similar to the buffing mark discovered during the first inspection. This suggests that the static acceleration was capable of producing displacer-to-cylinder contact. However, even with this temporary contact there is no measurable change in the convertor performance. One may then conclude that the convertor design is capable of the static acceleration loads anticipated during a mission. 


\section{Conclusion}

NASA Glenn Research Center has begun executing a series of durability tests that are intended to demonstrate the margins in the ASC design. A total of four tests were conceived. The tests were designed to overexpose the convertor without causing permanent damage to the hardware. The tests were designed to evaluate margins in four separate areas: potential wear due to start/stop cycles, response to static $\mathrm{g}$ loads in lateral and axial directions, potential contact events during launch vibration, and overstroke due to controller or operational error. Two of the four tests have been completed, and the third has begun. The latter two tests will take place during the remainder of 2012. The start/stop cycle test was completed in 2011. This test showed that the multiple start/stop cycles expected on a flight convertor will have no negative effect on the moving components. The centrifuge test showed that the convertor is capable of axial and lateral static $\mathrm{g}$ loads up to $18 \mathrm{~g}$ with no negative effect on the moving components.

\section{References}

1. NASA Discovery Program Mission News. http://discovery.nasa.gov/news/index.cfml? ID=1034, accessed November 9, 2012.

2. Oriti, S.M. (2011). "Extended Operation of Stirling Convertors at NASA Glenn Research Center," AIAA-2011-5726.

3. Meer, David W., Hill, Dennis, and Ursic, Joseph, "Advanced Stirling Convertor Dynamic Test Approach and Results," Proceedings of the 7th International Energy Conversion Engineering Conference, AIAA-2009-4552, Denver, CO, 2009. 



\begin{tabular}{|c|c|c|}
\hline \multicolumn{2}{|c|}{ REPORT DOCUMENTATION PAGE } & $\begin{array}{l}\text { Form Approved } \\
\text { OMB No. 0704-0188 }\end{array}$ \\
\hline \multicolumn{3}{|c|}{ 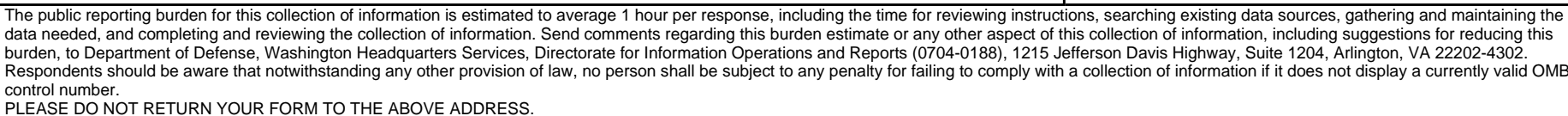 } \\
\hline $\begin{array}{l}\text { 1. REPORT DATE (DD-MM-YYYY) } \\
01-11-2012\end{array}$ & $\begin{array}{l}\text { 2. REPORT TYPE } \\
\text { Technical Memorandum }\end{array}$ & 3. DATES COVERED (From - To) \\
\hline \multirow{3}{*}{\multicolumn{2}{|c|}{$\begin{array}{l}\text { 4. TITLE AND SUBTITLE } \\
\text { Advanced Stirling Convertor Durability Testing: Plans and Interim }\end{array}$}} & 5a. CONTRACT NUMBER \\
\hline & & 5b. GRANT NUMBER \\
\hline & & 5c. PROGRAM ELEMENT NUMBER \\
\hline \multirow{3}{*}{\multicolumn{2}{|c|}{$\begin{array}{l}\text { 6. AUTHOR(S) } \\
\text { Meer, David, W.; Oriti, Salvatore, M. }\end{array}$}} & 5d. PROJECT NUMBER \\
\hline & & 5e. TASK NUMBER \\
\hline & & $\begin{array}{l}\text { 5f. WORK UNIT NUMBER } \\
\text { WBS } 138494.01 .99 .01\end{array}$ \\
\hline \multicolumn{2}{|c|}{$\begin{array}{l}\text { 7. PERFORMING ORGANIZATION NAME(S) AND ADDRESS(ES) } \\
\text { National Aeronautics and Space Administration } \\
\text { John H. Glenn Research Center at Lewis Field } \\
\text { Cleveland, Ohio 44135-3191 }\end{array}$} & $\begin{array}{l}\text { 8. PERFORMING ORGANIZATION } \\
\text { REPORT NUMBER } \\
\text { E-18225 }\end{array}$ \\
\hline \multirow{2}{*}{\multicolumn{2}{|c|}{$\begin{array}{l}\text { 9. SPONSORING/MONITORING AGENCY NAME(S) AND ADDRESS(ES) } \\
\text { National Aeronautics and Space Administration } \\
\text { Washington, DC 20546-0001 }\end{array}$}} & $\begin{array}{l}\text { 10. SPONSORING/MONITOR'S } \\
\text { ACRONYM(S) } \\
\text { NASA }\end{array}$ \\
\hline & & $\begin{array}{l}\text { 11. SPONSORING/MONITORING } \\
\text { REPORT NUMBER } \\
\text { NASA/TM-2012-217727 }\end{array}$ \\
\hline \multicolumn{3}{|c|}{$\begin{array}{l}\text { 12. DISTRIBUTION/AVAILABILITY STATEMENT } \\
\text { Unclassified-Unlimited } \\
\text { Subject Category: } 20 \\
\text { Available electronically at http://www.sti.nasa.gov } \\
\text { This publication is available from the NASA Center for AeroSpace Information, 443-757-5802 }\end{array}$} \\
\hline
\end{tabular}

\section{SUPPLEMENTARY NOTES}

\section{ABSTRACT}

The U.S. Department of Energy (DOE), Lockheed Martin Corporation (LM), and NASA Glenn Research Center (GRC) have been developing the Advanced Stirling Radioisotope Generator (ASRG) for use as a power system for space science missions. In support of this program, GRC has been involved in testing Stirling convertors, including the Advanced Stirling Convertor (ASC), for use in the ASRG. This testing includes electromagnetic interference/compatibility (EMI/EMC), structural dynamics, advanced materials, organics, and unattended extended operation. The purpose of the durability tests is to experimentally demonstrate the margins in the ASC design. Due to

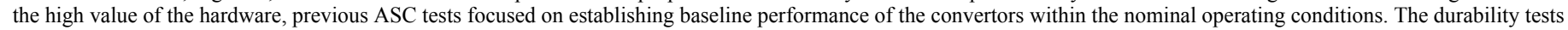
present the first planned extension of the operating conditions into regions beyond those intended to meet the product spec, where the possibility exists of lateral contact,

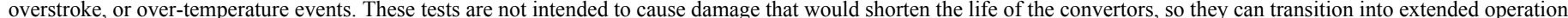

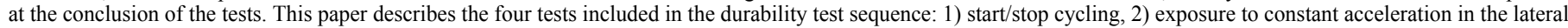
and axial directions, 3) random vibration at increased piston amplitude to induce contact events, and 4) overstroke testing to simulate potential failures during processing or during the mission life where contact events could occur. The paper also summarizes the analysis and simulation used to predict the results of each of these tests.

15. SUBJECT TERMS

ASRG; Radioisotope; ASC; Stirling

\begin{tabular}{|l|l|l|l|}
\hline \multicolumn{2}{|l|}{ 16. SECURITY CLASSIFICATION OF: } & $\begin{array}{l}\text { 17. LIMITATION OF } \\
\text { ABSTRACT }\end{array}$ \\
\begin{tabular}{|l|l|} 
a. REPORT \\
$U$
\end{tabular} & $\begin{array}{l}\text { b. ABSTRACT } \\
\text { U }\end{array}$ & $\begin{array}{l}\text { c. THIS } \\
\text { PAGE } \\
\text { U }\end{array}$ & UU \\
\hline
\end{tabular}

18. NUMBER
OF
PAGES
18

19a. NAME OF RESPONSIBLE PERSON STI Help Desk (email:help@sti.nasa.gov) 19b. TELEPHONE NUMBER (include area code) 443-757-5802 

